\title{
Societal Sentiment about Hima Das: A Narrative Analysis Using CAQDAS, ATLAS.ti
}

\author{
Ajay Gupta \\ \{ ajay1133@gmail.com \} \\ VESIM Business School, Affiliated to Mumbai University
}

\begin{abstract}
The purpose of the paper is to understand societal sentimental about "Hima Das Caste search" and study its influence on organizations. A strong trend emerged when people started searching for Hima Das caste after she won gold medal in the 400-meter final at U-20 IAAF, World Championship at Finland. We used Google search engine, Twitter and Google trends to collect data from11July, and 4.43 PM to 18July 2018, 4.43 PM, to understand the people search sentiment using ATLAS.ti qualitative assessment software. We used coding, memoing, making code families, networks and thematising the data. We analyzed data using narrative analysis and strong trend emerged state wise about caste search. The study has implication on organizations as they represents small segment of society. Such societal preference has potential to influence the growth of people and organizations adversely, as it is discriminatory in nature.
\end{abstract}

Keywords: Societal Sentiment, Narrative Analysis, ATLAS.ti, Coding, Discriminatory

\section{Introduction}

Discrimination in any form is the social evil- be it caste, creed, religious belief, gender, or color of skin. It starts from the infected minds. Many great leaders advocated for equality in terms of treating others. According to traditional theory Brahma, the creator of universe, created the caste system. Similarly, political theory advocates that Brahmins wanted to rule over society. Therefore, their political interest created a caste system in India. Further, caste system is the outcomes of the religious customs. And Kings and Brahmins were given higher positions. Further as per Nesfield, caste system was developed as per the occupation of the person. Jobs were leveled with superior and inferiors.

However, evolutionary theory states that caste system is just like other social institution and developed through the process of evolution. Professor Hutton propounded the many theory or theory of many. As per this theory, people avoid touching others on the basis of eating habits. This led to differentiation and discrimination. He also mentioned that caste system was there in India before Aryan.

The caste system becomes problematic when people use it for ranking purpose. When it leads to unequal access to natural and man-made resources, it becomes cancerous. Caste system leads to several evils in the society. It leads to untouchability and discriminatory practices. Various leaders such as Mahatma Gandhi, Jyotiba Phule and Dr. Bhimrao Ambedkar spoke against the caste system. 
As per Rig Veda (early Hindu text) there were four categories known as 'varnas'. Varnasconsist of Brahmins, Kshatriyas, Vaishyas and Shudras. Most of the historians still believe that today's caste system is based on these varnas. Also there was the fifth category that was even inferior to shudras and that was of "untouchables" or Dalits. These were the persons who used to perform tasks of removing faeces of dead animals. They were not allowed to enter into temples, drink from the same water source, etc. Untouchability is the most common form of discrimination that is based on the caste system in India.

According to article 14 of the Indian constitution, the state shall not deny equality to any person before the law or the equal protection of the laws within the territory of India. Article 15 prohibits the state from discriminating any citizen on ground of any religion, race, caste, sex, and place of birth or any of them.

The objective of this study is to understand the societal sentiment about "Hima das caste search" and analyze how organizations can learn lessons to restrain discriminatory practices that is detrimental to people and organizations.

After Hima Das clinched the top spot in the women's 400 meter final race in IAAF World under 20 athletics championship at Finland, a trend emerged where people searched for Hima Das caste on Google and various internet platform. This motivated the researcher to find the reason for such sentiments and how such sentiment may have influence on the organizations as organizations are small section the society.

\section{Caste system in India}

The caste system in India is a classification of people into Varnas which is further divided into sub castes called Jatis. Such classification is based on specific occupation to each hierarchy. The top position in the social hierarchy is monopolized by a few dominant castes [15]. The two upper castes are ritually considered as superior to the lower castes [19]. The Brahmans, usually priests and scholars, are at the top. And, Shudras are considered only capable of serving as slaves to the upper three classes. Further, Shudras are not permitted to read or learn the Vedas or recite the mantras. They are also not allowed to enter temples. They are known as untouchable and their presence can pollute the things. For example, their presence can pollute the temple. They are forbidden to enter the streets in which the houses of the upper castes are situated. Further they are destined to only in the outskirts of the village and were never an integral part of village community [10].In the past people believed that diseases could be spread not only through physical touch but through the air as well. This is one of the reasons why Dalits were not allowed to touch the high caste community and were required to stand a certain distance away from the higher castes [7]. Mixing of castes is not allowed because it is believed that the higher castes are more pure and less polluted than lower castes [17]. It is the clear signal of discriminatory practice.

This had impact on lower castes people. Around the 6th century, many individuals of the lower castes who were getting fed up of suppression turned to Buddhism. Buddhism actually began as a reaction to the violence of Hindu society, including the brutality of the caste system (Essortment). Buddhism concentrates not on the society, but on the individual, thus separating religion from the interests of the ruling and dominance. In Buddhism, one is no longer born into 
a position due to past injustice. Although Buddhism does see life as pain and suffering and reincarnation as a renewal of this suffering. Therefore, it is clear that conversion of Hindu into Buddhismis due to violence of Hindu society.

The Buddha, himself born into the warrior caste, was a severe critic of the caste system. Buddhism utterly rejects any system of caste, and it actually reached high levels of support during the rule of Ashoka, who adopted the Buddhist concept of ahimsa, or non-violence, and its tendency toward greater equality (Essortment). He ridiculed the priests who claimed to be superior, criticized the theological basis of the system, and he welcomed into his community people of all castes, including outcasts (Malalasekera and Jayatilleke). Buddha opposed caste system.

When the British government wanted to install a water system in Bombay, there was a great outcry at first from the upper castes. They could not believe that pure and impure, twice-born and Shudra, were going to be drinking from the same taps as themselves [2].

The effect of caste system was disastrous. Upper caste did not allow the untouchable to enter into their locality including temples. It was criminal offence. If such mindsets exist today, it can divide and discriminate people and create dysfunctional society.

\section{Research Objectives}

Organizations represent the tiny part of the society. They values, beliefs and virtues are passed on from the society. Therefore, social values, preferences, and sentiments have repercussion on the organizations. Good social values make healthy organizations and vice versa. Therefore, one objective of the research paper is to find out the influence of society sentiment about the caste on the culture, harmony, and environment of the organizations where people come from various societies.

People have different philosophies and customs working together to achieve the goal of the organizations. They are expected to coordinate their efforts and integrate resources to reach its purpose. It is possible when people have respect for each other. However, when it does not take place, organizations defy its purpose and fail to achieve the goal.

Therefore, the core objective of the research paper is to understand the societal sentiment and its drivers.

Secondly, how such societal preference can affect the growth of people across organizations and sectors. Finally, how management and employees can overcome such preferences by creating systems, processes and healthy practices.

\section{Research Methodology}

Our motivation for the study started from news flashing on various newspapers and websites. It includes digital platform like Google, twitter, and newspapers etc. Google search engine and twitter revealed the offending information about search habits of people worldwide about the 
Olympic player Hima das ${ }^{1}$, about her caste. Google published public information that people searched about Hima das caste record number of times after she won the 400 meter Olympic race at under 20 world athletics. She clinched the gold medal in the 400 meter final at U-20 IAAF World Championship held at Tampere, Finland on 10-15 July, 2018. It is also known as the World Junior Championship. She became the first Indian athlete to win gold. She took 51.46 seconds to claim the top position.

Google and various websites published horrifying news about people search habit about the winning player. People searched Hima das caste number of times worldwide. Google and twitter criticized the habit of people. Instead of celebrating the success of the players, people were more interested to know her caste.

This incidence raised our curiosity to understand the phenomenon and how such preference could influence the organization across sectors. Similar incidence took place in the year 2016 when PV Sindu, Indian badminton player won silver medal at Rio Olympics and became the 5th Indian women player who a Olympic medal and first women to win a silver medal in Olympic games. People also searched for her caste.

We took qualitative approach to collect narratives and stories of various people across world. Using ATLAS.ti, qualitative assessment software, we conducted narrative analysis to understand the societal preference.

\subsection{Data Analysis}

We used narrative analysis to understand the societal sentiment. Narrative analysis is perhaps the best form of analysis where research involves thematising the research based on people statements, comments, critics, appreciations, or any opinions etc. Narrative analysis focuses on collecting, categorizing, grouping, and deriving themes out of narratives, stories, and opinions etc.

\subsection{Narrative Analysis}

Narrative inquiry is stories live told [4], and is rooted in different social and humanities discipline [8]. Narrative analysis has a specific focus on stories told by individuals [6]. Narrative can be both a method and the phenomenon of study [14]. Therefore, we studied the stories under the specific phenomenon. And we collected data from google, google trends, and twitter related to Hima Das after she won the 400 meter final at U-20 IAAF World Championship. We collected texts and stories within the context of India and worldwide.

The process of narrative analysis starts with collecting descriptions of events or happenings and configuring them into a story using a plot line [16]. In the present study we studied the context of caste of Hima das as narrative study has a specific contextual focus [13], and the stories told about organizations (6). Clandinin and Connelly offered general methods of conducting a narrative study [4].

\subsubsection{Determine if the research problem or question best fits narrative research}

\footnotetext{
${ }^{1}$ She became the first Indian to win a Gold medal in a track event at the World Junior Athletics Championships in 2018
} 
Narrative research is best for capturing the detailed stories or life experiences of a single life or the lives of a small number of individuals.

\subsubsection{Gather stories through multiple types of information}

They are also referred as field texts [4]. Researcher may also collect letters sent by the individuals, assemble stories, gather documents such as memos, obtain photographs, or any other personal, family, and social artifacts.

\subsubsection{Collect information about the context of these stories}

Narrative researchers situate individual stories within participants' personal experiences (their jobs, their homes), their culture (racial or ethnic), and their historical contexts (time and place).

\subsubsection{Analyze the participants' stories, and then "restori' them into a framework that makes sense}

Restorying is the process of reorganizing the stories into some general type of framework. This framework may consist of gathering stories, analyzing them for key elements of the story (e.g., time, place, plot, and scene), and then rewriting the stories to place them within a chronological sequence [13].

Stories should have chronology [5] such as main character, beginning, middle and an end. It involves a conflict, struggle, predicament, a protagonist, and a sequence with implied causality [3]. The story might include elements such as time, place, and scene. The plot, or story line, may also include three-dimensional narrative inquiry space (4): the personal and social (the interaction); the past, present, and future (continuity); and the place (situation). This story line may include information about the setting or context of the participants' experiences.

Beyond the chronology, researchers might detail themes that arise from the story to provide a more detailed discussion of the meaning of the story. Thus, the qualitative data analysis may be a description of both the story and themes that emerge from it.

We used feelings and opinions of the respondents and analyzed them into descriptive form. Finally, we offered findings based on various descriptions categorized together to form a meaning.

\subsection{Data Collection}

We used three platforms to collect the data- Google search engine, Google trends, and twitter. Google search engine provided the number of search preference about Hima das caste. It also provided information about how people reacted about such preferences. It included various newspapers and websites that published the news about caste search. This was the first point of data collection. Besides, we also collected data about PV Sindhu caste search in similar incidence that took place in 2016. The reason, we wanted to understand the people sentiment commonalities and variances.

Secondly, we wanted to see the worldwide search trend. We were curious to know what emerges out of people preference. So, we used Google trends to find out people search preferences for the last 07 days. We collected worldwide data including United States and India. We left many countries where search preference was negligible. In India, we collected data state wise as well. This was our second data point. 
The third data point was twitter. We collected twitter information about Hima das. We used ATLAS.ti to collect data from twitter for the past 07 days. ATLAS.ti has feature to collect desired data for the past one week. We used \# (hash tag) to collect data. For example \#Hima Das Caste was the main search on twitter. We treated all the data as a document to analyze it. We created document group such as data from Google, data from Google trends, and data from twitter etc.

\subsection{ATLAS.ti Process}

We used ATLAS.ti to analyze data using narrative analysis method. We collected all the narratives expressed on Google, trends on Google trends and stories on twitter from 11thJuly, 4.43 PM to 18thJuly, 2018; 4.43 PM. One of the logic was that ATLAS.ti extracts data from twitter for the past 07 days only. We collected the data from Google search engine about "HimaDas Caste" search for the same period and searched trend from Google trends for the same period.

After collecting the data, we treated the information as our documents (in ATLAS.ti document is known as transcript or interview or primary source of information). We assigned documents in the ATLAS.ti. Then we started coding process that includes highlighting key information and giving them unique code. In the document having information extracted from Google, we started coding process first. For example Google search showed various search preferences about Hima das caste search. We coded such information as Hima das caste search.

Secondly, we started coding the information collected from the Google trends about the worldwide search preference of the people. We coded the key concepts that were useful to understand the people sentiments.

Third, we extracted all the tweets about Hima das for the past 07 days. To do this, we used ATLAS.ti 8, export/import function. After collecting the twitter data, we generated code cooccurrence to find out the strength of the concepts. To support the emerged concepts, we created networks that showed how various codes were linked together.

Finally, we produced report about people search preference about Hima das caste and correlated with the PV Sindhu caste search in 2016 in the similar incidence. Further, we provided key message across language that included congratulations, and felicitations. It also included criticizing people search preferences about the caste. We created plot that included everything including narratives, texts, images, sentiments and linked them to narrate the stories.

Finally, we discussed how organizations can learn from such incidence and ensure to overcome the effect of people sentiment. Policy makers can create policy measures to tackle such menace on organizations. Top management can take effective measure to learn how "caste sentiment" can adversely affect the culture of the organization. It can ruin the soft fabrics of working environment and eventually lower the employees' motivation and morale. Finally, it can negatively affect the performance, competitiveness, creativity, and innovation.

Organizations, management, leaders, and regulators can help people and organization to create healthy and nurturing place to happily work like human being without having any bias or pre conceived opinion about their colleagues. 


\section{Findings}

After coding process, we categorized codes in various concepts based on its similarities and characteristics. For example under archaic mindsets, the number 6 represents the number of quotations or useful information emerged under each document. So, archaic mindset has 6 key quotations under Google search engine, and 8 key quotations under twitter. Similarly, all the key concepts have been represented and subsequently shown in network and textual form. Quotations are the key statement under the specific emerged concept. The details of each concept has been discussed and shown in network view.

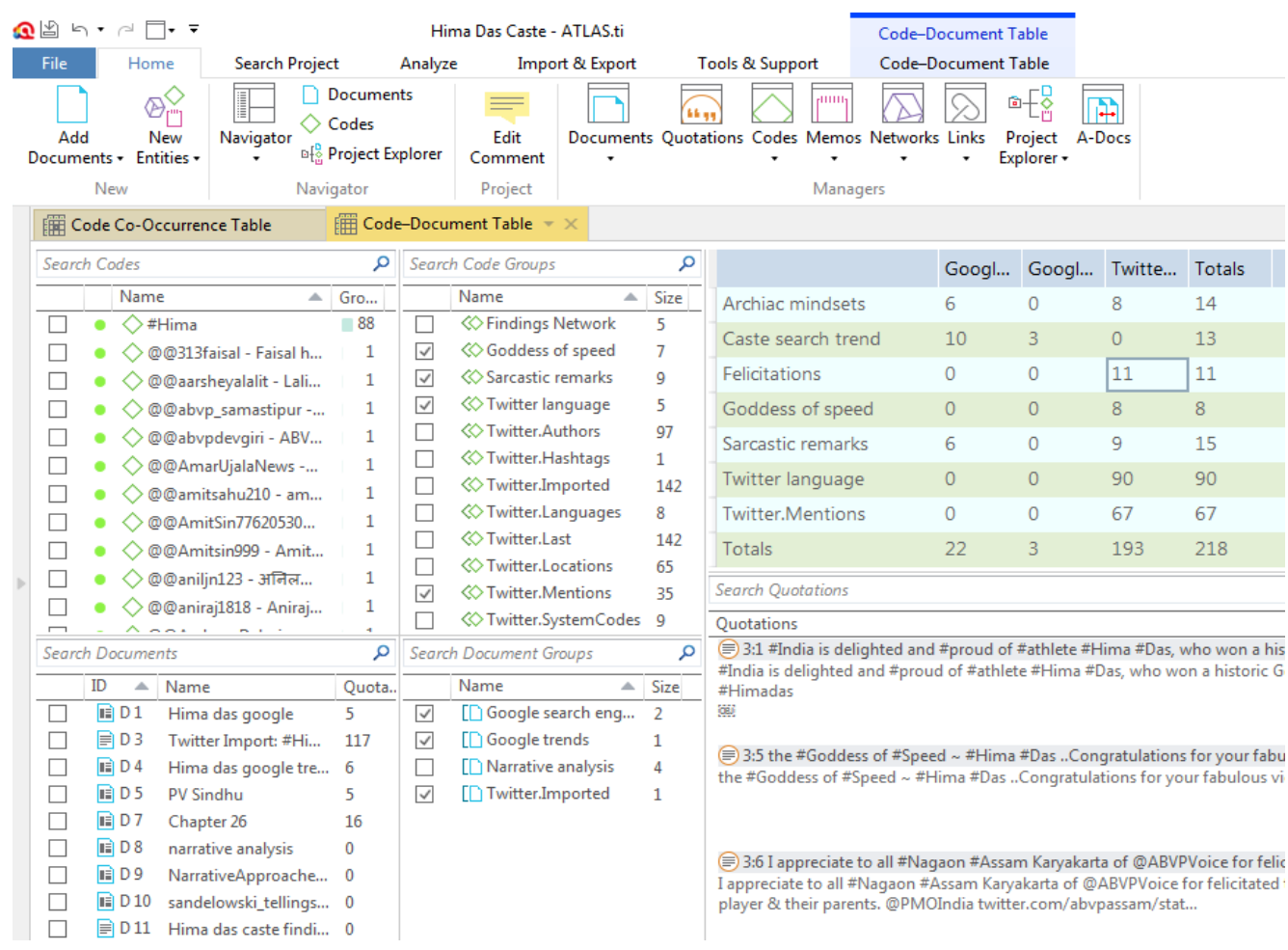

Figure 1: Code-document table

In the circle, various concepts have been shown as code groups, and the number represents the number of codes connected to the code group. 
The graph below is further representation of emerged concept that has been shown above. It helps to understand the number of quotations under each concept.

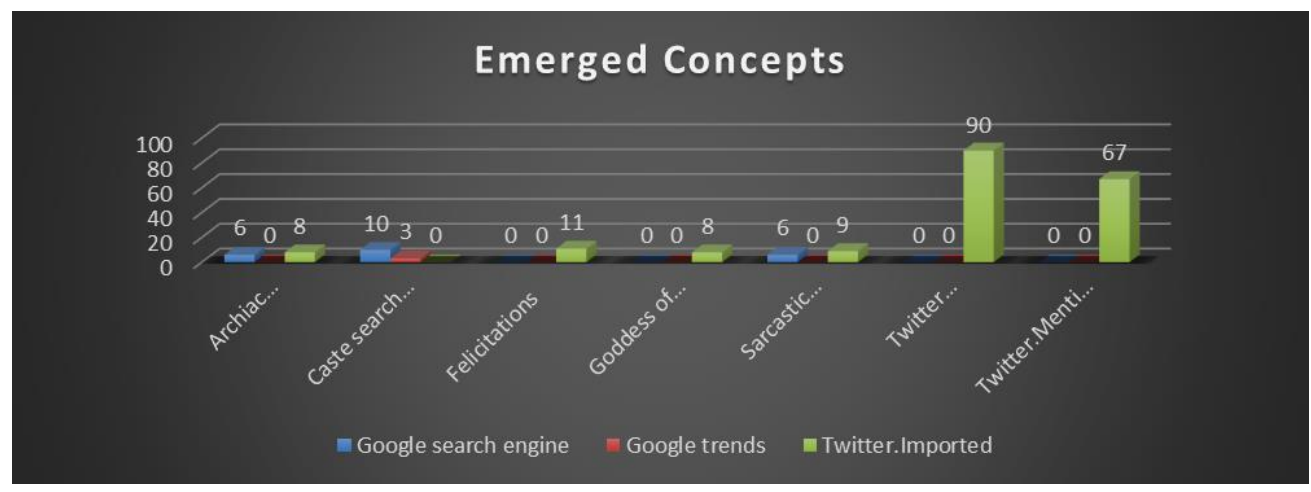

Figure 2: Emerged Concepts

\subsection{Networks of Emerged Concepts}

The network has been created by ATLAS.ti 8 that shows the Google information about Hima das caste search. Hima das caste had been searched 37,100 times from 11th July to 18th July, 2018. Other connected news show how various newspapers and people criticized people preference to search for the caste of winning player.

We linked Google trend data with Google search engine to explore relationships. Google trends data shows worldwide search preference. We explore state wise search preference to understand the people sentiment. Similarly, we also collected information that took place in year 2016 when PV Sindhu, Indian Badminton player won the game. People also searched about her caste number of times.

Therefore, in the networks, we have represented the relationship between people preference about similar situation in the past as well. Further, we have shown the caste search preference in case of PV Sindhu in the next network.

The network below shows the number of tweets, retweets and various news channels and people who congratulated Hima Das through their tweets. There were 88 tweets and 57 retweets along with 23 tweets by ABVP voice, and 22 tweets from ShreehariBorikar and 79 English language tweets. The linkage shows the connection and association among various nodes that provide information about Hima das. 


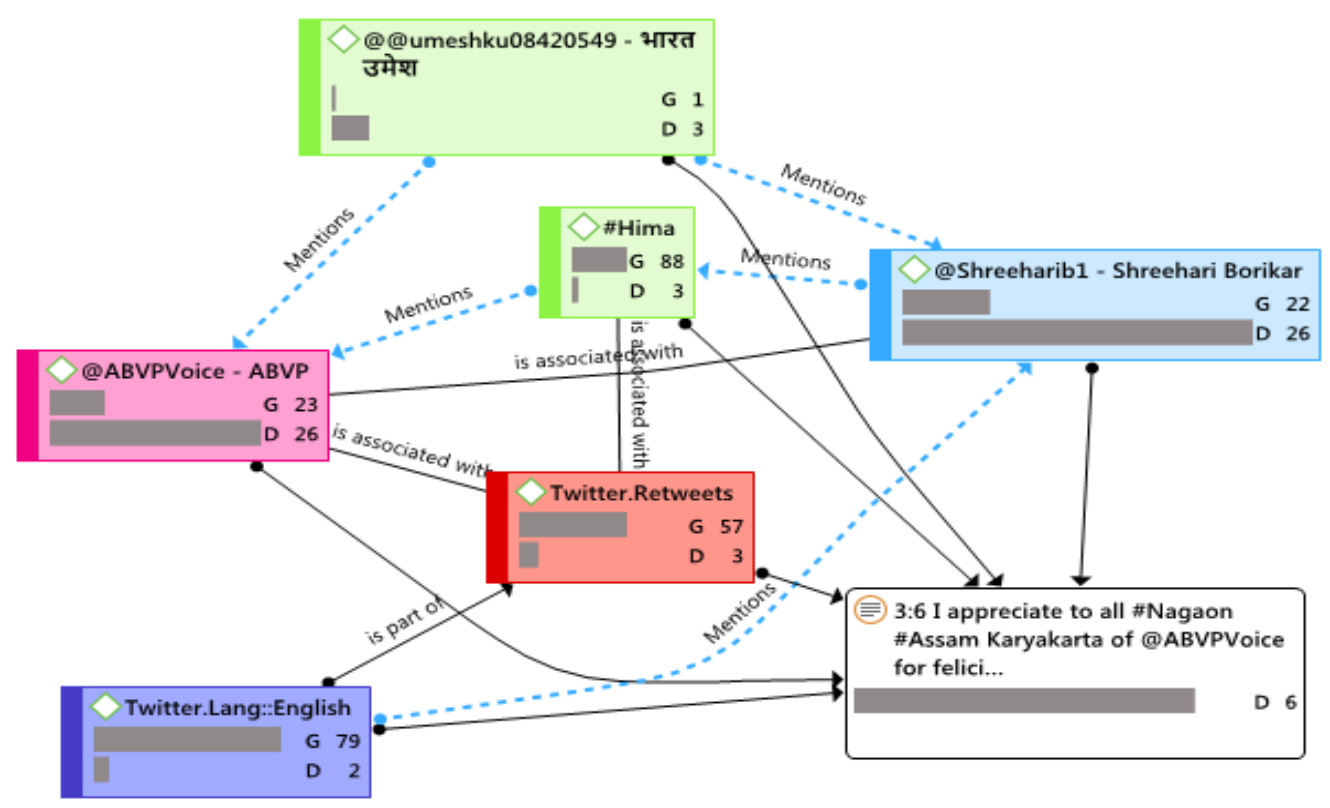

Figure 3: Tweets about Hima Das

The surprising trend emerged from Google trends where Kerala (figure 9) was number one in Hima das caste search followed by Karnataka, Andhra Pradesh, and Puducherry whereas the least search was from Madhya Pradesh, Rajasthan, Bihar, and Odisha etc.

In terms of language used on twitter, besides English, there were tweets in many languages such as Hindi, Kannada, Marathi, Gujarati, Spanish, and German etc.

There were three tweets related to the caste. They criticized the people effort to search for the caste of Hima das.

We represented the tweets related to congratulations in different language below ATLAS.ti cooccurrence tool represents the codes recurrence. Co-occurrence shows the strength of the concept. In other words, these emerged concepts have rich description and co-occur across the concepts. The tweets are extremely encouraging, inspiring, and stimulating in nature.

It clearly shows how a group of people are really appreciative and concerned about the extraordinary of the success of Indian player. People have expressed their feelings in various other languages. Some of tweets have been shown below.

\subsection{Felicitation Network}

The network view shows the code that emerged from the data. $G$ represents the groundedness of the information. In other words, groundedness represents the key quotation under the concept. After the network view, the quotations have been described below. 


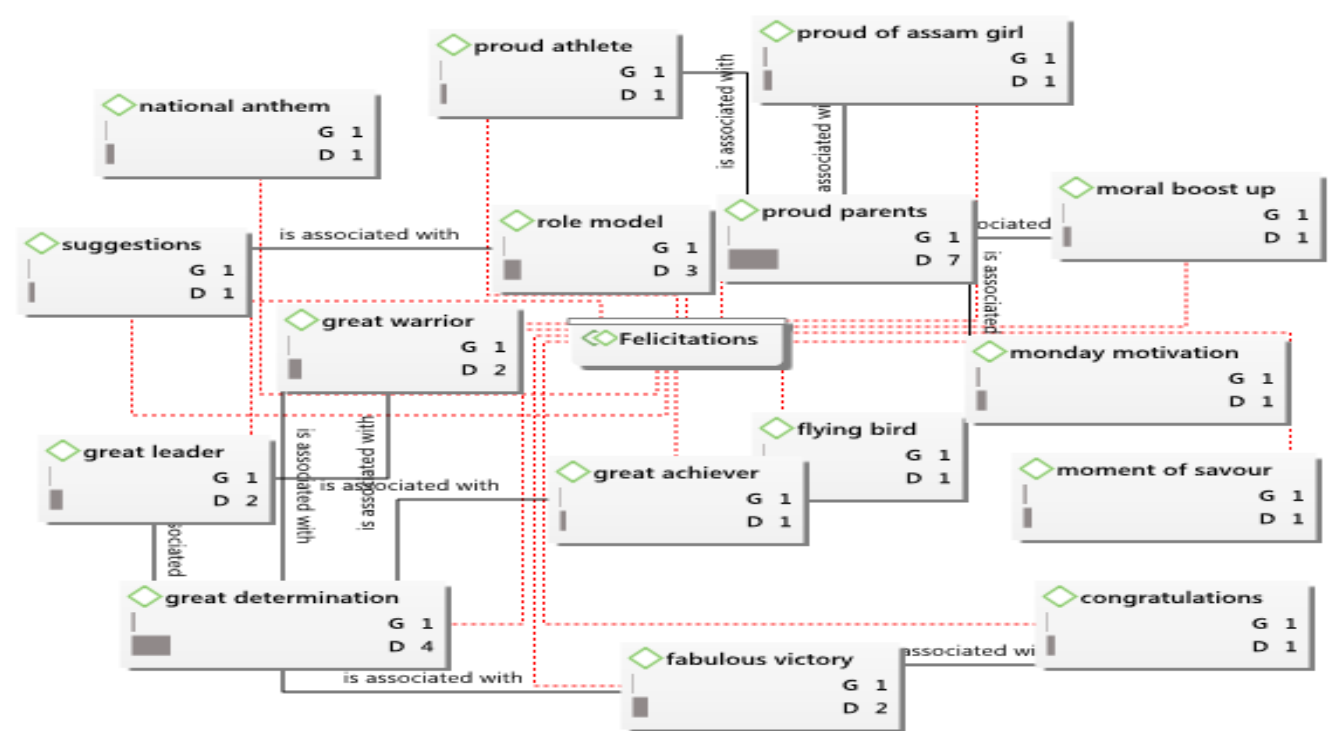

Figure 4: Felicitation Network

- \#India is delighted and \#proud of \#athlete \#Hima \#Das, who won a historic Gold in the 400m of \#World U20 \#Championships. \#Congratulations to her! \#Himadas

- I appreciate to all \#Nagaon \#Assam Karyakarta of @ABVPVoice for felicitated the Mother \& Father of \#Hima Das. Such activities boost up the moral of every player \& their parents. @PMOIndia twitter.com/abvpassam/stat...

- Our \#Monday Motivation for this week is a no-brainer! She's the first Indian to win gold at the IAAF World Under-20 Athletics Championships. Here's to \#Hima Das, her determination, and her incredible effort. \#Havells wishes more power to her!

- Great leaders,greatwarriors,greatachievers, will almost always comes from a miserable background...in fact that kind of pain makes everyone to be like most successful...\#hima das u made our country proud.......the emotion she got about... increasing the value of India twitter.com/GautamGambhir/...

- Congrats \#hima das. You are a role model for \#girl power in India. You are also an inspiration for millions of young people.\#Youth Power@UNICEFIndia @aditi1231

- $\quad$ Proud of Assam girl \#hima das.

- The new flying bird of India: Hima Das.

- RESPONSIBILITIES \#WOULD \#BE \#TAKEN \#BY \#INDIA \#TILL \#TOKYO \#OLYMPICS, 2020.

- $\quad$ Getting emotional while singing the\#NATIONAL ANTHEM touched me deeplyJai hind, Bharat mataki jai

- Tears rolling down her cheeks, \#HimaDas sing the Indian National anthem after receiving the Gold medal. A moment to savor 


\subsection{Archaic Mindset}

HimaDas' caste highly searched on Google; Twitterati criticize 'archaic' mindset Indian express. Hima das caste was searched on the Google 37,100 times that have been shown below. Similarly, we can see the Google search result about people search preference on Google about Hima das.

Interestingly, Hima das is not the first athlete, but similar search took place in year 2016 when PV Sindhu, badminton player became the first Indian woman to win a silver medal after a heartbreakingly close badminton final at Rio Olympics 2016-Quartz.Aug 19, 2016² . Google showed the people preference to search her caste 2100 times $^{3}$ in August, 2016.

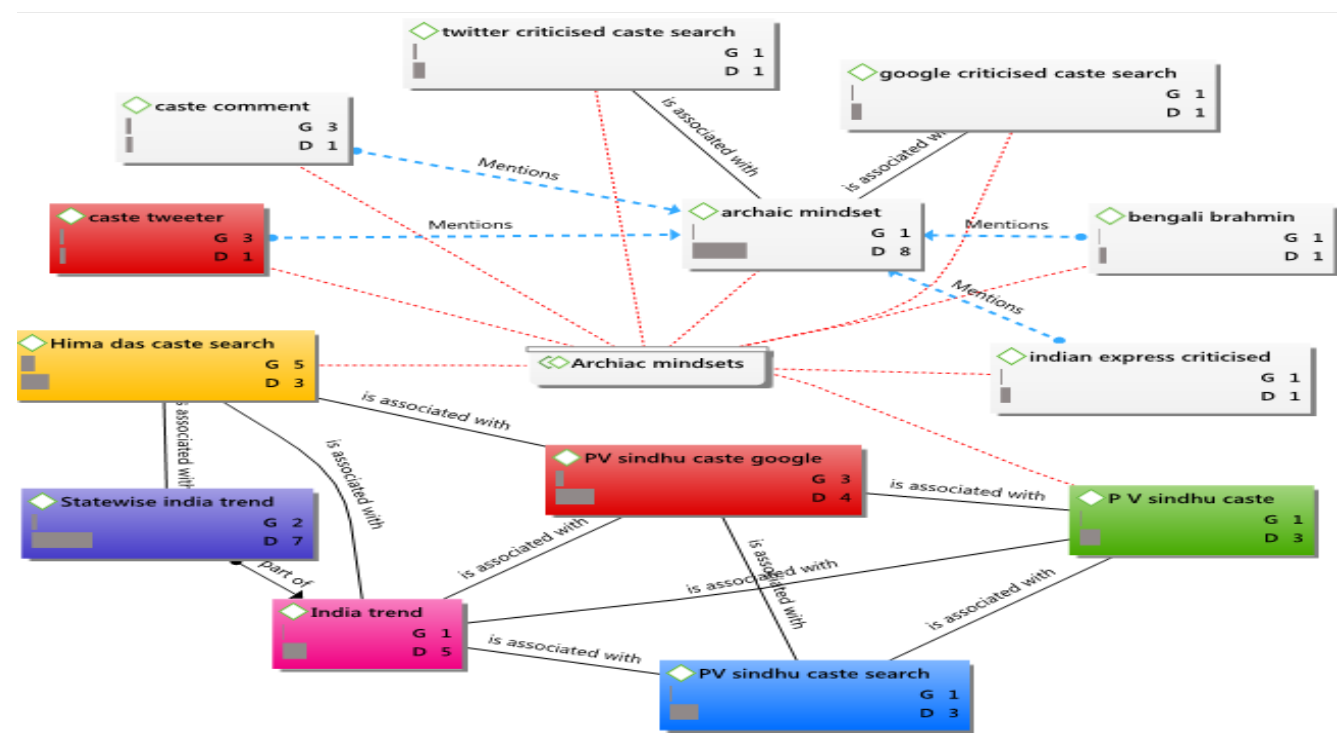

Figure 5: Archaic Mindset

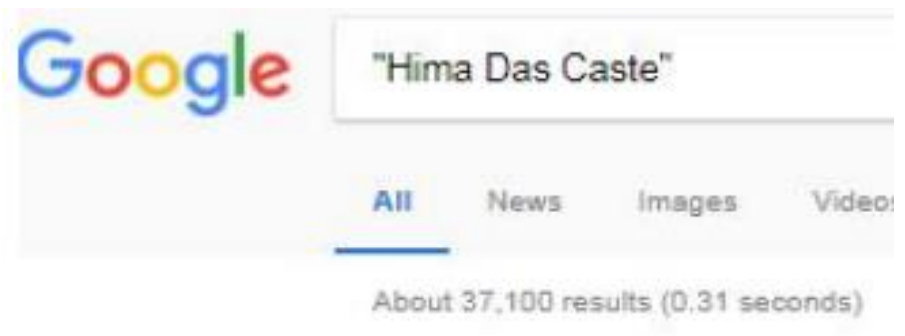

Figure 6: Caste Search Hits

\footnotetext{
${ }^{2}$ https://qz.com/762041/pv-sindhu-is-the-first-indian-woman-to-win-a-silver-medal-after-aheartbreakingly-close-badminton-final/ accessed on $27^{\text {th }}$ July, 2018

${ }^{3} \mathrm{https}$ ://thelogicalindian.com/news/the-reports-of-millions-of-indians-searching-p-v-sindhus-caste-isfalse/ accessed on $29^{\text {th }}$ July, 2018
} 


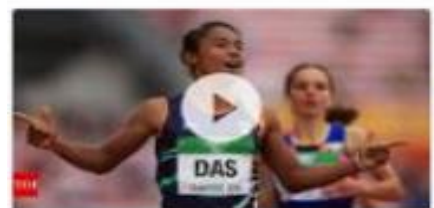

People are searching Hima Das on Google but not for what you might think

Times of India

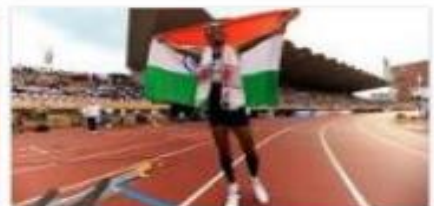

The Outrage Over 'Hima Das Caste' Was Overblown; If You Really Want To End..

Swarajya

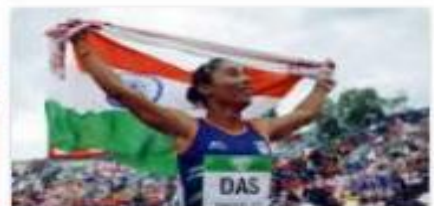

Hima Das Made History And Indians Jumped In To 'Search' Her Caste On Google

HuffPost India

Why the 'urban elite' wants to know Hima Das's caste - Dailyo https: //Www dailyo in/variety/hima-das-caste-gold-medal of $125503 \mathrm{html}$. 2 days ago - The phrase 'Hima Das caste' promptly sppears as a search suggestion as types her name in the Google search bar. [Screenshot].

Hima Das: People are searching Hima Das on Google but not fc https:/timesofindia. indiatimes.com/india/people-are hima. $/ 65006276 . \mathrm{cm} s$. 2 days ago - Yes. efter her name. 'Hima Das caste' is the most searched topic about he Equally surprising, though, is the Twitter backlash ...

The Outrage Over 'Hima Das Caste' Was Overblown; If You Rea https://swarajyamag com $/ . . /$ the-outrage-over-hima-das-caste-was-overblown-if-yo 1 day ago - There is actually a simple way in which to show casteism the door. It is to stc

\section{PV Sindhu's caste highly sear Google, reveals ingrained bia}

Andhra Pradesh, Telangana and Haryana are the top three states whe

Written by Tarishi Verma | New Delhi | Published: August 20, 2015 3r38:30 pm.

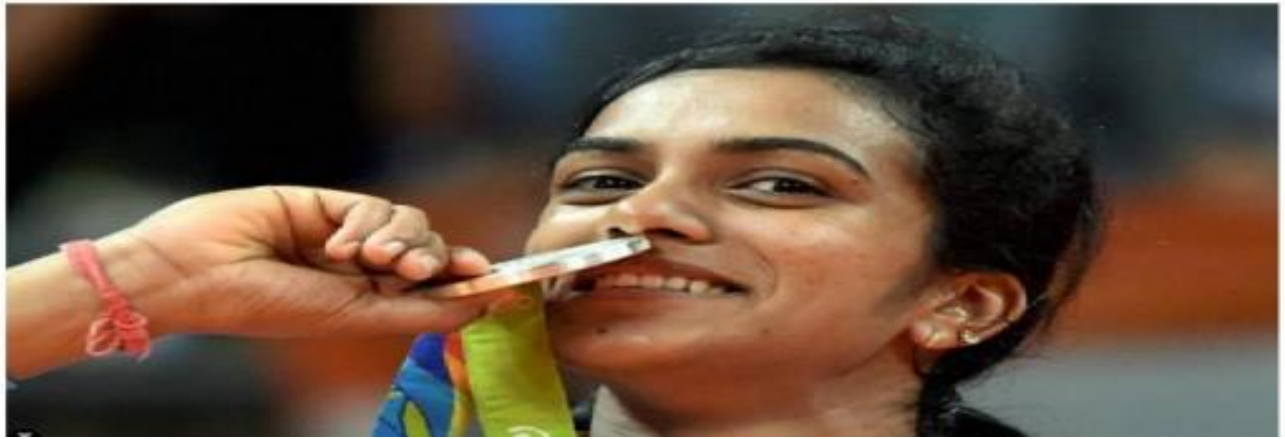




\subsection{Sarcastic Remarks}

Many comments were sarcastic in nature. One of the comments was about the importance of English language. Two other comments mentioned about her caste.

- If English is so important then let's send SashiTharoor for Olympic nect time \#AFI \#Hima Das

- \#hima das caste

- Such an Inspire, \#Hima Das, \#Gold, \#Bengali Brahmin, \#Age 18

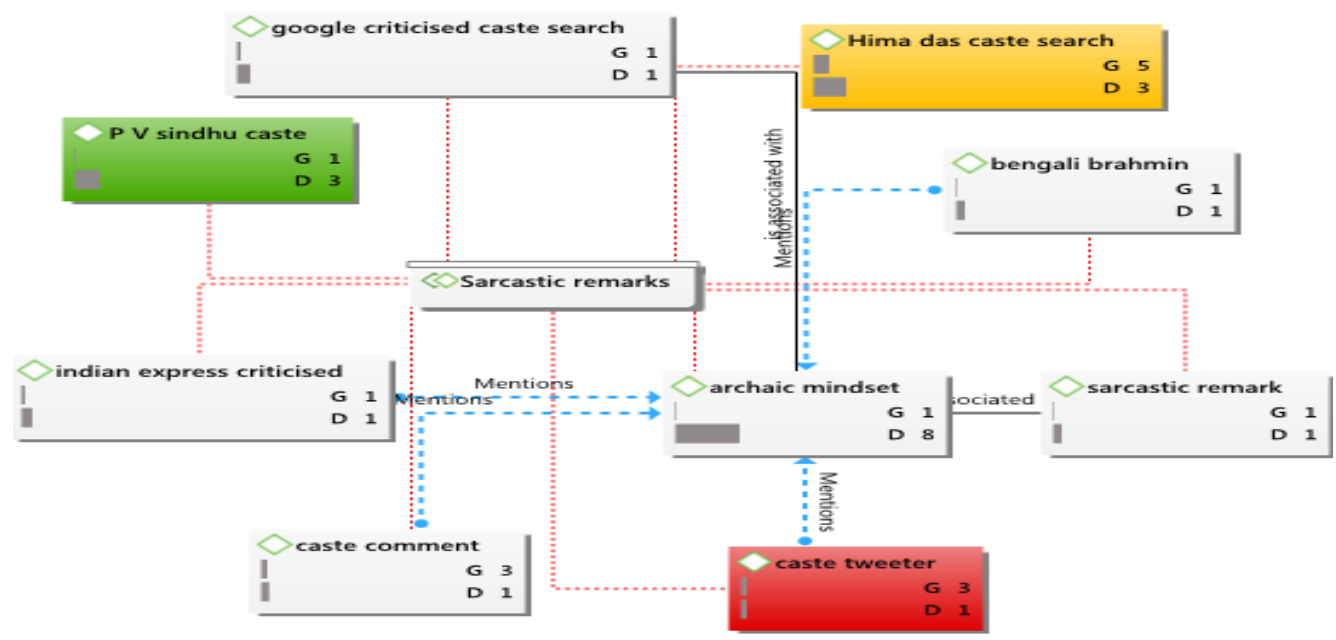

Figure 7: Sarcastic Remarks

\subsection{Goddess of Speed}

Many comments on twitter were appreciative and encouraging. Some comments mentioned Hima das as goddess of speed. Key tweets are given below.

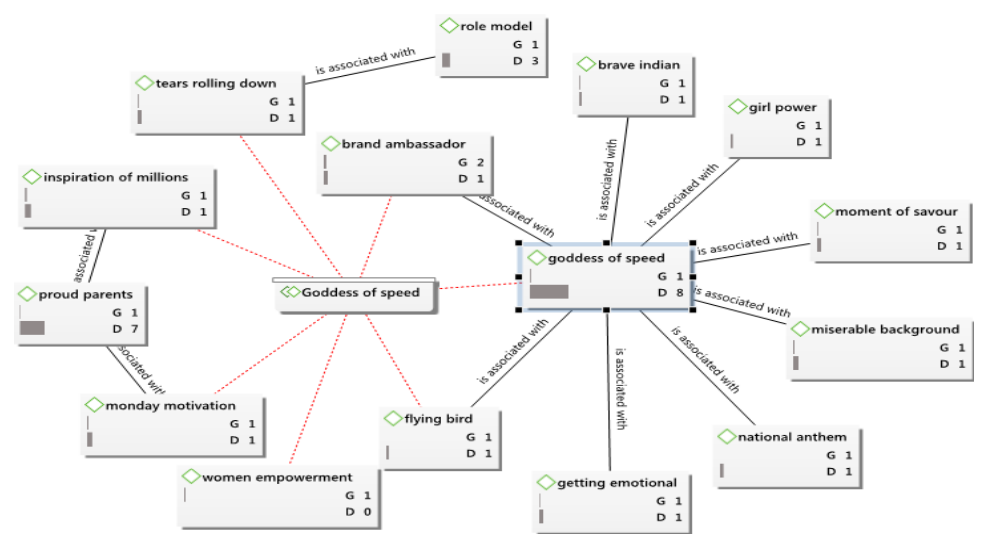

Figure 8: Goddess of Speed 
- The \#Goddess of \#Speed \#Hima \#Das. Congratulations for your fabulous victory! You deserve it every bit! Hats off such a \#brave \#fellow \#Indian

- Prompt decision from CM and Sports minister of \#Assam. \#Hima Das made brand ambassador of the state. Now she needs coaching at \#USA/\#JAMAICAN clubs. Target Olympic Gold.

- We are \#Indian proud of them. This is called women empowerment. We salute them

- The new flying bird of India: Hima Das.

- Heartiest congratulations on winning Gold at the World U20 athletics championship.

- Had Tears In Her Eyes While Proudly Singing The National Anthem.

- A thousand words in those tears!

- Thank you, Hima Das.

\subsection{Caste Search Trend}

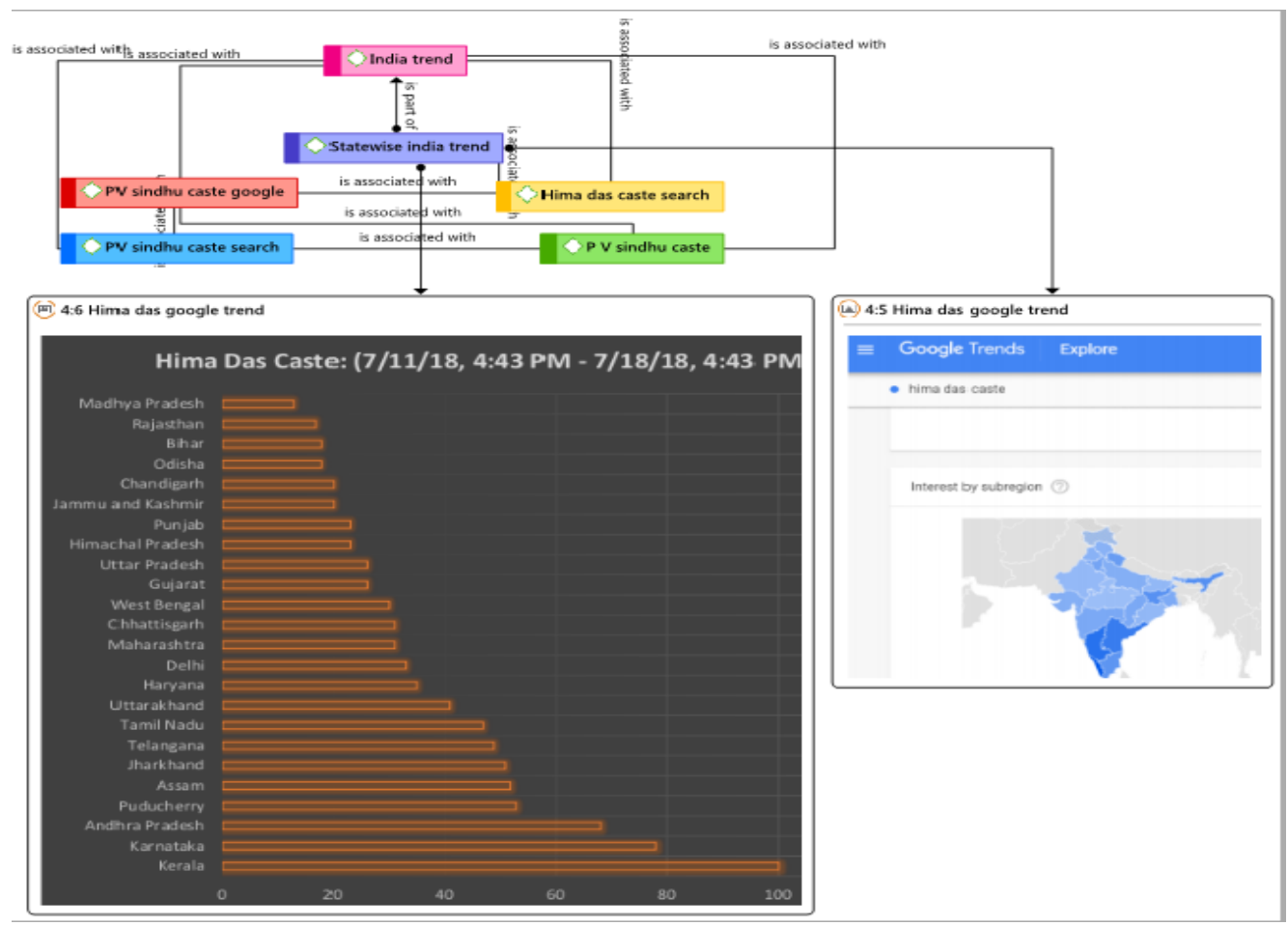

Figure 9: Caste Search Trend

The most heartbreaking trend was caste search about the winning player. We explored to understand the trend state wise and result surprised us. Kerala, the most literate state was the number in caste search followed by Karnataka, Andhra Pradesh, and Puducherry etc. The state 
wise trend has been shown in the figure 9. Image from Google trends support the claim. This is not the new trend. In the similar incidence, PV Sindhu, badminton player caste was searched 2100 times in the year 2016 when she won silver medal in Rio Olympics.

\section{Narrative Analysis}

Mixed reactions about Hima das showed that people are divided on the basis of their caste, region, gender, and background etc. There are section of people who try to link success with the caste whereas there are group of people who are appreciative about the success of the player. Similar incidence took place in the year 2016 with PV Sindhu when she won silver in Rio Olympics. Google showed people preference to search about the caste of the player. Surprisingly, google trends data showed clear linkage of literate state preference about such search. The most literate state search was the highest.

However, almost all the tweets were positive and encouraging in nature. People appreciated her incredible determination and efforts. This incident will boost the morale of players and parents of India. With this great achievement, Hima das will be role model of the players. She will also become role model for girl players. Many people felt proud in saying that Hima das is the daughter of a farmer. She is an inspiration for the entire nation and the world. Many tweeted about her origin saying her Assam girl, proud of her, golden girl etc.

They related the background of Hima das and expressed that leaders emerge from the miserable situation. Hima das showed that she is a true leader.

Some tweets were related to her caste. For example, one tweet mentioned her Bengali Brahmin. Many people criticized the people preference about searching about Hima das caste.

Most of the tweets were encouraging and motivating in nature. People mentioned her daughter of the nation. She was the first Indian woman to win gold. She is the goddess of speed and new flying bird of India. Many people expressed their views that Hima cried while national anthem was played. In fact, this was a matter of pride for all of us. She was immediately made the brand ambassador of Assam state. For this fabulous victory, people suggested to prepare for the Tokyo Olympic in 2020.

The question is not why their caste is important or the trappings of the Indian mindset, but who is making "caste" an inseparable part of our system. Who is responsible for continuing the centuries-old caste hierarchy?

This system is surely not a hangover from the past, because hangovers don't last so long.

Truth be told, this discrimination is part of our social administration, and like all other institutions, this is run under organized supervision. It is not even a rustic reverence based on ignorance and lack of education that has kept the system alive. It has often been argued in fact that a severe lack of public education and awareness are responsible for caste discrimination enduring in India. The country and its policy-makers initially believed that caste-based reservation would help contain the scourge, closing the gap between "upper and lower castes" - bringing the underprivileged on a par with the more privileged, correcting historical wrongs. But instead of closing the gap, caste-based reservation has seemingly highlighted the chasm. 
In a country with limited public resources, long-term reservations raised large-scale disgruntlement among various "upper caste" Indians who suddenly found themselves on the other side of the scale in terms of social, economic and political opportunities. As the reservation policy kept expanding - adding new categories and sub-categories - more because of political compulsions, and less economic considerations, the resentment too kept increasing.

As a result, caste-based discrimination is still very much a part of our lives in India. If anything, the hierarchy of caste in its modern avatar looks more menacing, with highly educated, empowered Indians resorting to malicious displays of casteism and frequently justifying this.

A very real danger to Dalit/SC/ST/OBC communities is not from proposed laws or dilution of policies, but from the belligerent display of casteism by educated "upper castes" on social media. Elite India wraps its revulsion for the "lower" caste in dangerously distasteful WhatsApp forwards, Twitter and Facebook posts - messages that make it clear why such elites feel compelled to Google Das's caste.

Do we need more proof of who is more bothered about Hima Das's caste? It's not the "rural, illiterate" bunch whose lack of awareness is often blamed for the continuing caste system. In fact, it is the urban drawing rooms and high-tech smart phones from where such caste consciousness arises. It is the urbane mindset which likes to claim it doesn't discriminate between people on the basis of caste - yet perpetrates harsh caste prejudices and stereotypes all too often.

There is a strange ignorance of such elite minds.

Beneath their well-informed, erudite facade lies the dangerous lack of awareness that even they don't seem to be aware of. For instance, some well-informed people could connect with Hima instantly based on her surname, which in India works mostly as a caste identifier.

\section{Recommendations and Suggestions}

Organizations are made of people represent the society. They carry the values, beliefs, virtues, sentiments, social norms, rituals, cultural beliefs along with them. Whether they work in private sector, public sector and family owned enterprises, they behave in alignment with the organization and their belief. Therefore, any dysfunctional belief or sentiment that can divide and discriminate people on the basis of social, physical and attribution measures create dent on the people and organizations. In impact the motivational level of the employees especially who are targeted and are vulnerable.

Similarly, such mindsets in the organization can influence hiring process and career chart of the employees. As a result, it has potential to create toxic work culture and inharmonious employees' relationship. Management and leadership can create system and processes where each employee is respected. Any effort that divide and discriminate people on caste, creed, or community basis can be avoided.

Instead of celebrating the fabulous success people were more concerned about searching her caste. Google search engine showed 37,100 hits for "Hima Das Caste" search on 18th July, 2018. When we further searched to know the state wise preference, we were surprised to see the 
result available on Google trends from 11th July, 2018 to 18th July, 2018. In the similar incidence, PV Sindhu caste was searched 2100 times in the year 2016.

The most literate state showed the maximum search result ${ }^{4}$. Similarly, least literate like Madhya Pradesh, Rajasthan, Bihar, and Odisha showed the least search about the Hima das caste search. This preference was criticized by Google, twitters, national and international newspapers.

This shows the people preconceived feelings about the person. It appears they wanted to correlate success with the social background of the player. We are not sure why people were searching for Hima das caste but it is clear that people have clear understanding of social hierarchy of caste system and they measure people on their social status or caste. This clearly indicates that such preference can create division among people and society.

Organizations are ocean of people where people come from different region, religion, caste, creed, gender, orientation, social status, and orientation etc. They are expected to align with the purpose of the organization in order to achieve organizational goals. When they align their effort, enthusiasm, and passion, organizations can reach to any level and remain competitive. However, organization may fail to achieve its desired purpose, when people have divided in terms of their caste, gender, identity, orientation, region, and religion etc.

Therefore, this poses the great challenge to the organizations and its management to ensure neutralizing such mindsets and viruses. This is a serious issue for the organizations and society as well. If it prevails, the most deserving and sincere employees from the less privileged section may get demotivated and less deserving people might showcase their fake commitment. Organizations should devise mechanism to ensure people are treated with respect and dignity without any kind of discrimination on the basis of caste, color of skin and region etc.

Therefore, we suggest organizations to take precautionary measures to ensure the nonrecurrence of such habits. This sentiment has enough potential to derail the organization from achieving its vision and breakthrough success. If unchecked, this might spread like H1N1 virus that is hard to cure. Further, it can take the shape of malignant cancer that is fatal and extremely dangerous. It may grapple many healthy employees with incurable disease.

This will have multiple impacts on the organizations in tangible and intangible forms. Employee motivations will plummet and hence they are more likely to feel the heat of disappointment, discouragement, and disrespect. This will adversely impact the performance, profitability and brand value.

Similarly, this will create different faction and clique within the organization. People are more likely to associate with their social caste hierarchy and might discriminate with the people with lower social hierarchy.

\footnotetext{
${ }^{4}$ Interest by sub region. See in which location your term was most popular during the specified time frame. Values are calculated on a scale from 0 to 100 , where 100 is the location with the most popularity as a fraction of total searches in that location, a value of 50 indicates a location which is half as popular. A value of 0 indicates a location where there was not enough data for this term. Note: A higher value means a higher proportion of all queries, not a higher absolute query count. So a tiny country where $80 \%$ of the queries are for "bananas" will get twice the score of a giant country where only $40 \%$ of the queries are for "bananas."

(https://trends.google.com/trends/explore?date=now\%207-d\&geo=IN\&q=hima\%20das\%20caste)
} 


\section{Future Direction of Research}

Leaders, management, researchers, consultants, faculty, and managers can take up the project to explore the effect of such symptoms on the organizations across sectors. Research on such issues is generally ignored in the industrial organizations. It is better to use qualitative research from various sections of people to understand the depth of this menace. Further, they can use quantitative research to find its reach. This might provide overview of the people and organization dynamics that is detrimental to the growth of people and organization.

Policy makers can devise policy to ensure the healthy practices and good people governance across the organizations. Management can provide training related to attitude, behavior, emotional intelligence etc. Finally, they can take corrective measure to root out such unhealthy and anti-employee practices. If possible, they can take severe measure in the best interest of people and organizations.

\section{References}

[1] Ambedkar, B. R. (2014). Annihilation of caste: The annotated critical edition. Verso Books.

[2] Bouglé, Célestin. Essays on the Caste System. London: Cambridge UP, 1971. Print.

[3] Carter, K. (1993). The place of a story in the study of teaching and teacher education. Educational Researcher 22, 5-12, 18.

[4] Clandinin, D. Jean, and F. Michael Connelly. 2000. Narrative Inquiry. Experience and Story in Qualitative Research. San Francisco: Jossey-Bass Publishers.

[5] Cortazzi, M. (1993). Narrative analysis. London: Falmer Press.

[6] Czarniawska, Barbara. 2004. Narratives in Social Science Research. Introducing Qualitative Methods.

[7] Daniel, Aharon. "Caste System in Modern India." Adaniel's Info Site. Web. 4 Nov. 2010.

[8] Daiute, Colette and Lightfoot, Cynthia. 2004. Narrative Analysis. Studying the Development of Individuals in Society. Thousand Oaks, London, and New Delhi: Sage.

[9] Deshpande, M. S. (2010). History of the Indian caste system and its impact on India today.

[10] Hampton, Andrea. "The Untouchables." Home - CSU, Chico. Web. 23 Nov. 2010

[11] https://trends.google.com/trends/explore?date=now\%207-d\&q=hima\%20das\%20caste accessed on 18th July, 2018.

[12] https://twitter.com accessed on 18th July, 2018.

[13] Ollerenshaw, J. A., \& Creswell, J. W. (2002). Narrative research: A comparison of two restorying data analysis approaches. Qualitative Inquiry, 8, 329-347.

[14] Pinnegar, S., \&Daynes) J. G. (2006). Locating narrative inquiry historically: Thematic in the turn to narrative. In D. J. Clandinin (Ed.), Handbook of narrative inquiry. Thousand Oaks, CA: Sage.

[15] Pintane, Andrea. "Brahmans within the Caste System." Home - CSU, Chico. Web. 11 Oct. 2010.

[16] Polkinghorne, Donald E. 1988. Narrative knowing and the human sciences. In SUNY Series in Philosophy of the Social Sciences, edited by L. Langsdorf. Albany: State University of New York Press. 
[17] Pyakurel, Sourav. "Caste System in India | Articles." Rajput Brotherhood: A Blog Focused on Technology and Web-development. Web. 29 Nov. 2010.

[18] Roy, A. (2017). The Doctor and the Saint: Caste, Race, and Annihilation of Caste, the Debate between BR Ambedkar and MK Gandhi. Haymarket Books.

[19] Smith, Brian K. Classifying the Universe: the Ancient Indian Varna System and the Origins of Caste. New York: Oxford UP, 1994. Print. 